\title{
RE-USING EXPERT CHOICE MODELS IN MULTI-PROJECT ENVIRONMENTS
}

\author{
Christine Xiaoyi Dai and Scott Serich \\ Project Management Program, Management Science Department, The George Washington University \\ 2101 F. St. NW, Bldg. AL, Room 301, Washington, DC 20052 \\ cdai@gwu.edu, serich@acm.org
}

Complex decisions face the modern project manager at many points in the project life cycle, from project evaluation to vendor selection. These decisions are often characterized by multiple evaluation criteria requiring subjective assessments. They also demand an approach that is flexible enough to enable sensitivity analysis corresponding to changes in underlying assumptions. Such changes are becoming more prevalent as more organizations adopt the project management paradigm, install project management offices (Block and Frame 1998, Cleland and Kerzner 1985), and move toward project management as an organization-wide competence.

This paper demonstrates how an AHP-based tool such as Expert Choice® (Forman et al, 1996) can be used to facilitate making complex decisions across multiple projects. While the underlying scientific and mathematical foundations of AHP are quite sophisticated, Expert Choice shields the user from many of these intricacies. It can perform vivid sensitivity analyses and enables rapid diagnosis of inconsistencies in ordering preferences. Such features are particularly important to project managers who, compared to their functional management counterparts, are expected to command a much broader range of management skills. Robust, user-friendly tools such as Expert Choice can help mitigate the cognitive burdens placed on these managers.

Mian and Dai (1999) demonstrate the use of Expert Choice to assist project selection, bid evaluation, schedule compression strategy, evaluation of ongoing projects, and selection of a project manager. The current study presents an Expert Choice model to illustrate how the project manager selection model described in that previous study can be modified and re-used across multiple projects.

The goal of the original model presented in Mian and Dai (1999) was to select the best of three project manager candidates based on three criteria: (1) Administrative and Supervisory Skills, (2) Technical Knowledge, and (3) Personal Abilities. The relative weights assigned to these criteria were, respectively, $62.5 \%, 23.8 \%$, and $13.6 \%$, and the corresponding relative scores for each of the three candidates were $44.9 \%, 37.4 \%$, and $17.7 \%$ (see Figure 1 ).

Suppose now that a second project is seeking to fill its top position, but the evaluation criteria for that project's sponsor are different from those for the first project.

The Dynamic Sensitivity Analysis mode in Expert Choice allows the user to easily re-use the original model, making changes in relative weights with a minimum of time and effort. The relative weights for the new project are changed to $79.9 \%, 10.1 \%$, and $10.1 \%$. The corresponding relative scores are reflected in real-time in the Dynamic Sensitivity Analysis display (see Figure 2).

Note that under the new relative weighting system, candidate 2 has surpassed candidate 1 as the most desirable project manager for this new project, with relative scores of $40.9 \%$ and $38.6 \%$, respectively.

The project management office can utilize this model to help potential project sponsors identify the type of manager with whom they will feel most comfortable for a particular project. This can serve overall 
organizational goals by mitigating the risk of failure during later phases due to a mis-fit between desired and assigned project manager skills.

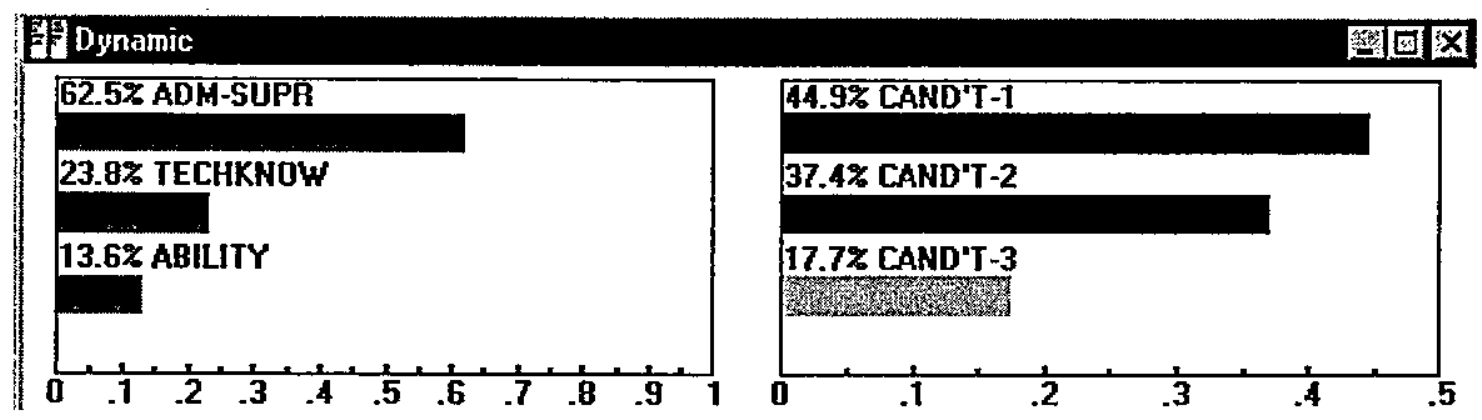

Figure 1 Dynamic Sensitivity Analysis for Original Project

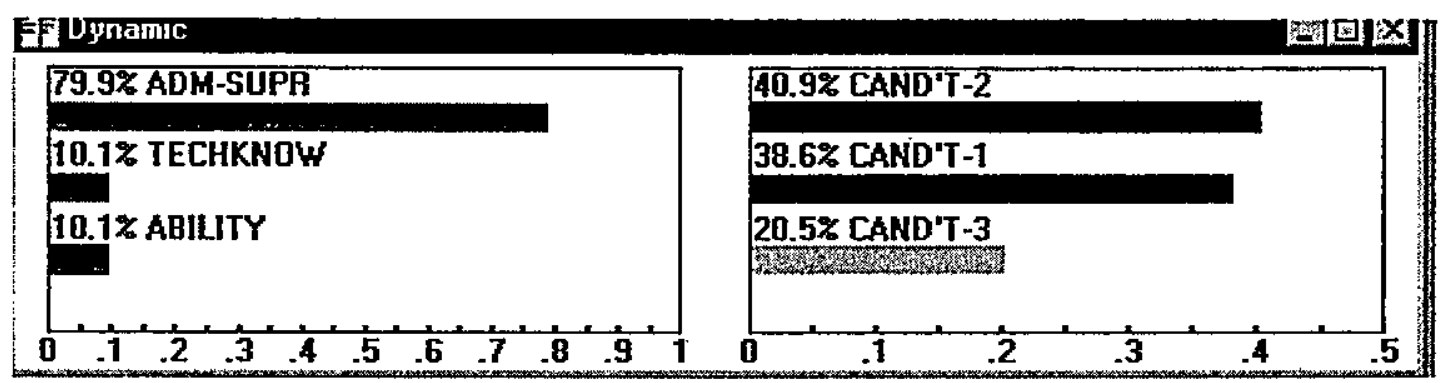

Figure 2 Dynamic Sensitivity Analysis for New Project

\section{References}

Block, T. R. and Frame, R. D. (1998) The Project Office: A Key to Managing Projects Effectively, Crisp Publications, Menlo Park, CA

Cleland, D. I., and Kerzner H. (1985) A Project Management Dictionary of Terms, Van Nostrand Reinhold Company, New York

Forman, E. H., Saaty, T. L., Selly, M. A., and Waldron R. (1996) Expert Choice, Decision Support Software, Inc., McLean, VA

Mian, S. and Dai, C. X. (1999), "Decision Making Over the Project Life Cycle: An Analytic Hierarchy Approach", Project Management Journal, March, 30:1. 